\title{
Informação visual e controlo postural durante a execução da pirouette no ballet
}

\author{
Renata A. Denardi \\ Marcela C. Ferracioli \\ Sérgio T. Rodrigues
}

https://doi.org/10.5628/rpcd.08.02.241

\author{
Laboratório de Informação, Visão e Ação (LIVIA) \\ Departamento de Educação Física \\ Faculdade de Ciências \\ Universidade Estadual Paulista \\ Brasil
}

\begin{abstract}
RESUMO
Um aspecto fundamental do sistema visual que subsidia a aquisição de informação relevante para o controle postural de bailarinas, o movimento dos olhos e da cabeça, foi investigado durante a execução da pirouette, um giro do ballet clássico. Oito bailarinas experientes foram analisadas com (olhos abertos normalmente) e sem (olhos vendados) informação visual disponível, com o objetivo de (i) testar a hipótese de associação entre maior duração da fixação do olhar antes do início do giro e melhor performance motora, (ii) averiguar a validade de dicas dos instrutores de ballet sobre como "marcar a cabeça", e (iii) verificar o efeito da disponibilidade de informação visual no controle postural das bailarinas. Os resultados não corroboraram a hipótese de alta correlação negativa entre duração da fixação inicial e instabilidade postural, mas revelaram longos períodos de fixação antes do giro e reduzidas oscilações corporais. A indisponibilidade de informação visual deteriorou significativamente a estabilidade postural. Um nítido sequenciamento dos giros do tronco, cabeça e olhar foi observado, mostrando a pertinência das dicas dos instrutores de ballet.
\end{abstract}

Palavras-chave: informação visual, comportamento do olhar, controle postural, ballet

\section{ABSTRACT \\ Visual information and postural control during pirouette execution in ballet}

\begin{abstract}
A fundamental aspect of the visual system that supports visual information acquisition relevant to postural control of ballet dancers, eyes and head movements, was investigated during the execution of a pirouette, a turn of classical ballet. Eight expert ballet dancers were analyzed with (opened eyes) and without (blindfolded eyes) visual information available in order to (i) test the hypothesis of association between longer gaze fixation turn initiation and better motor performance, (ii) check the validity of ballet instructors' cues on how to "set the head", and (iii) verify the effect of availability of visual information on postural control of ballet dancers. The results did not corroborate the hypothesis of high negative correlation between initial fixation duration and postural instability, but they revealed long initial fixation durations and reduced body oscillations. The unavailability of visual information deteriorated significantly the postural stability. A clear sequence of trunk, head and gaze turns was observed, showing the adequacy of ballet instructors' cues.
\end{abstract}

Key-words: visual information, gaze behavior, postural control, ballet 


\section{INTRODUÇÃO}

A execução de giros, como a pirouette, é considerada uma tarefa complexa no ballet clássico. Além da força necessária para girar, obtida através da combinação da flexão dos joelhos e de movimento de braços, uma estratégia particular de "marcar a cabeça" é usada. Esta estratégia, sob investigação no presente trabalho, envolve movimento dos olhos e da cabeça, aparentemente na busca de sincronização da informação visual e comandos musculares apropriados para a manutenção do equilíbrio postural. Há literatura restrita sobre o papel e as características da visão em dançarinos, embora informação visual seja crucial para eles se orientarem e adequarem suas posições no espaço, garantindo o sucesso do movimento e da coreografia.

Dados sobre o movimento dos olhos possibilitam o entendimento dos mecanismos de aquisição de informação visual relevante para o controle das ações motoras. As pessoas percebem o ambiente com os olhos-na-cabeça-sobre-um-corpo-sobre-osolo, e não simplesmente com os olhos( ${ }^{(4,5)}$. Em situações como as de giro, há uma busca de estabilização do olhar, um processo que minimiza as conseqüências rotacionais ao fluxo na retina, que parece ser vantajoso para otimizar a obtenção da informação oriunda do movimento translatório da cabeça e do tronco(3).

Na ação da pirouette, a aquisição de informação visual depende do movimento de tronco, cabeça e olhos imediatamente antes e durante o giro. O fluxo translatório originado pelo movimento do complexo tronco-cabeça informa sobre a estrutura tridimensional do espaço em relação ao corpo da bailarina. O fluxo rotatório, que é gerado pelo movimento dos olhos em relação à cabeça, informa justamente sobre a diferença entre posição dos olhos e da cabeça; por exemplo, no início do giro, os olhos são mantidos à frente enquanto tronco e cabeça já iniciaram a rotação. É evidente a busca de estabilização do olhar pela bailarina, procurando manter a cena visual instável (o que ocorre quando o olhar faz a rotação) pelo mínimo tempo possível; assim, o olhar é o último a deixar a direção à frente do corpo e o primeiro a alcançar a mesma direção, logo após o giro.

$\mathrm{O}$ avanço recente da tecnologia necessária para medir movimento dos olhos tem permitido a investi- gação de tarefas esportivas e do cotidiano em seus ambientes naturais. O acoplamento entre comportamento visual e motor tem sido estudado em uma variedade de atividades, como na estabilização dos olhos e da cabeça no alvo numa situação de basquetebol(11), nas fixações na bola, alvo e taco durante batida do golfe em diferentes níveis de habilidade(15), na localização, número e duração de fixações em arremessos de lance livre do basquetebol(16), na perseguição visual da bola nas tarefas de recepção e passe do voleibol(18), na perseguição visual e estabilização do olhar de mesatenistas iniciantes e experientes durante a batida forehand (12), no comportamento visual no tênis de mesa sob efeito da ansiedade(21) e em casos de hiperatividade / déficit atencional ${ }^{(19)}$, na coordenação de olhos, cabeça, tronco e pés durante movimentos de corpo inteiro(8), no olhar em jogadores de elite de hóquei no gelo durante tarefa de defe$\mathrm{sa}^{(9)}$ e no comportamento do olhar em situações de alta velocidade nos patinadores de velocidade ${ }^{(17)}$. O conceito de "olho quieto" (OQ, do termo inglês quiet eye) foi criado em um estudo que analisou arremessos de lance livre do basquetebol, no qual as variáveis foram a localização, o número e a duração das fixações durante arremessos com e sem sucesso de experts e quase-experts ${ }^{(16)}$. Definiu-se OQ como o período de tempo de início da fixação final em uma localização crítica da cena até o primeiro movimento observável das mãos na ação do arremesso. O fato de OQ ser anterior ao início do movimento é importante porque assume que a fixação é utilizada para processar aspectos críticos da imagem e definir parâmetros da ação a ser executada, uma vez que quando o movimento é iniciado, há pouca chance de correção. Uma hipótese de localização-supressão foi formulada, estabelecendo que uma duração de fixação longa numa localização alvo (como o aro do basquetebol) é necessária inicialmente, sendo terminada para dar lugar à supressão da visão, com piscadas e movimentos sacádicos.

O papel da informação visual no controle postural no contexto do ballet tem sido examinado em poucos estudos, como a comparação das habilidades posturais de dançarinas profissionais e judocas de alto nível(10), a análise de dançarinos em uma gangorra livre sobre a qual eles tinham que tentar manter o equilíbrio(6) e a determinação do grau de 
dependência da visão para o controle postural de bailarinos sobre uma plataforma livre(7). De modo geral, tem sido demonstrado que a restrição sensorial (condição sem visão) limita os padrões de controle postural: a estabilidade postural é sempre deteriorada na ausência de informação visual e a visão contribui diretamente para a redução de oscilações posturais.

Em suma, há indicativos da importância e da forte dependência da disponibilidade de informação visual para o controle da postura em situações dinâmicas. Características como a duração e a localização do olhar têm sido descritas como bons preditores da capacidade de controlar tanto o sincronismo de partes do corpo com objetos e planos do ambiente, como controlar a postura de modo global.

Assim, o objetivo do presente estudo foi testar a predição segundo a qual a fixação do olhar anterior ao início do giro $(\mathrm{OQ})$ está associada à qualidade de performance motora ${ }^{(16)}$; espera-se que fixação mais longa esteja fortemente correlacionada à menor instabilidade postural da pirouette. Adicionalmente, buscou-se confirmar a estratégia de controle do olhar na pirouette ensinada por profissionais do ballet, que sugere que o melhor equilíbrio corporal nesta tarefa é obtido através da definição de uma referência espacial para o olhar e da menor ausência possível de contato do olhar com esta referência (i.e., duração do giro do olhar). Buscou-se ainda distinguir entre os possíveis efeitos da visão sobre a estabilidade postural, através da manipulação da disponibilidade de informação visual.

\section{MÉTODO}

\section{Participantes}

Oito bailarinas das cidades de Bauru e Botucatu, Estado de São Paulo, Brasil, com idades entre 16 e 21 anos [média $(\mathrm{M})=18,5$; desvio-padrão $(\mathrm{DP})=$ $1,7)$, acuidade visual normal ou corrigida para normal, com pelo menos 6 anos de experiência em ballet clássico $(M=11,6 ; \mathrm{DP}=3,3)$, participaram como voluntárias do presente estudo. Antes do experimento, as participantes assinaram um Termo de Consentimento Livre e Esclarecido, que descrevia os procedimentos experimentais aos quais foram submetidas, conforme as exigências do Comitê de Ética em Pesquisa da Faculdade de Ciências da
UNESP - Campus de Bauru e em conformidade com a Declaração de Helsinque de 1975.

\section{Equipamentos}

Duas câmeras de vídeo (Sony CCD-TR2300 e Panassonic M9000) com freqüência de gravação padrão $(60 \mathrm{~Hz})$ e formato VHS, foram utilizadas neste estudo. Uma câmera foi posicionada no plano frontal, focalizando os olhos da participante; outra câmera, suspensa por um aparato de ferro fixado perpendicularmente e próximo ao teto da sala, focalizou cabeça e ombros da participante, em vista superior (Figura 1). Uma televisão (Sony KV 29T76) foi utilizada para auxiliar no ajuste da posição dos olhos da participante e na melhor localização de uma claquete. $\mathrm{O}$ fechamento desta claquete no início de cada tentativa foi utilizado para sincronizar as imagens das duas câmeras.

Um computador tipo PC (Processador Pentium III, $1.6 \mathrm{GHz}$ ), equipado com uma placa de aquisição de sinais de vídeo (Pinnacle DC 10 Plus), e acoplado a um videocassete (Panasonic NVSD25), foi utilizado para digitalização das imagens gravadas em vídeo. $\mathrm{O}$ software Studio 8 (Pinnacle Systems) foi o responsável pelo processo de digitalização e edição das imagens do movimento das participantes. O software Digital Video for Windows (Laboratório de Biomecânica e Instituto de Computação - UNICAMP, 1998 - versão 4) foi utilizado para os procedimentos de fotogrametria das imagens digitalizadas. O software Matlab (The Math Works Inc. - versão 5) foi utilizado para o cálculo das variáveis de interesse. O software SPSS (SPSS Inc., 1999 - versão 9) foi utilizado para as análises estatísticas necessárias.

\section{Procedimentos}

As participantes, após chegarem ao Laboratório de Informação, Visão e Ação (LIVIA), nas dependências da Praça de Esportes da Unesp - Campus de Bauru, leram e assinaram o Termo de Consentimento. Inicialmente, cada bailarina foi submetida a uma sessão de aquecimento, seguida da execução livre de tentativas de prática para familiarização com a tarefa e com o local de coleta de dados. A tarefa de cada participante foi executar cinco repetições do movimento pirouette en dehors em quinta posição dos pés (Figura 2) em cada uma das condições do experi- 


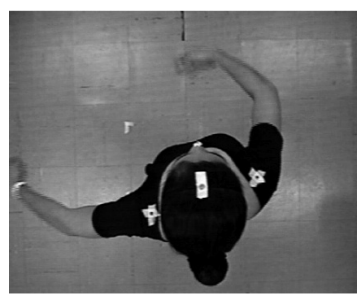

Q 28

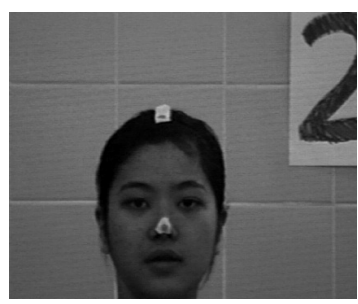

031

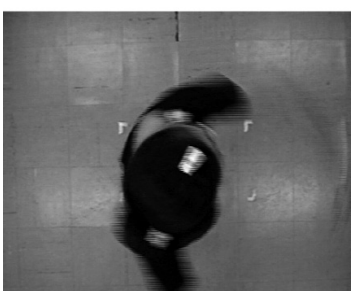

046

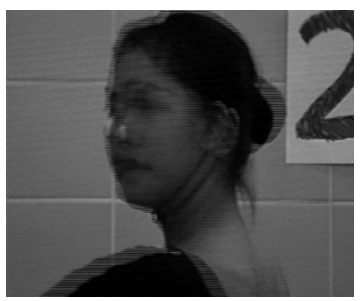

044

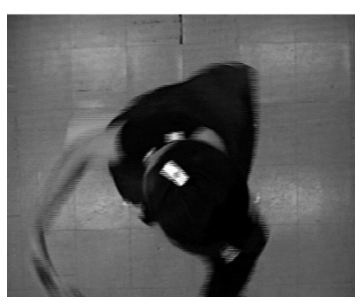

050

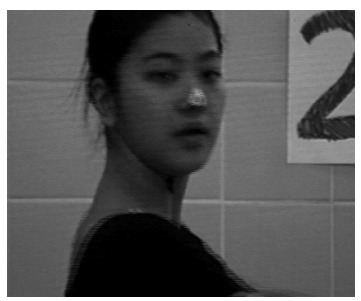

050

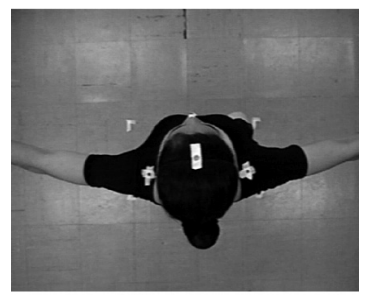

063

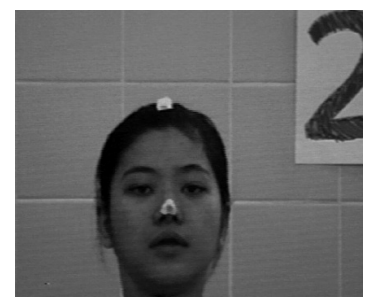

063

Figura 1. Quadros de vídeo nas perspectivas das câmeras superior (acima] e frontal (abaixo], representando as fases da execução da pirouette. A letra " $\emptyset$ ", seguida pelo número, indica o quadro de vídeo.
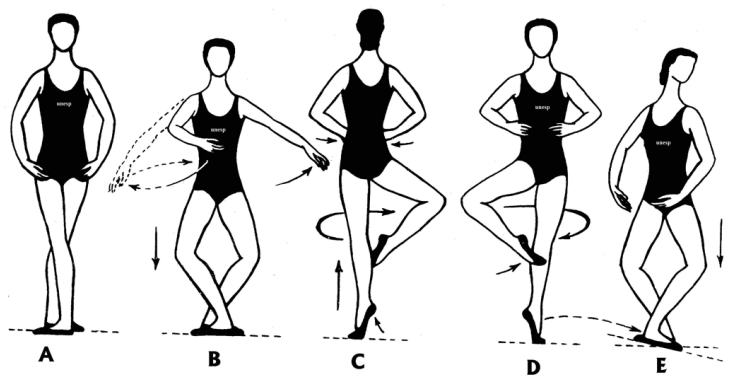

Figura 2. Representação gráfica dos movimentos da pirouette en dehors em quinta posição dos pés (1). Este giro é realizado no sentido da perna a ser elevada (e.g., sentido horário para elevação da perna direita), com o pé de apoio em meia-ponta (2C e 2D), com os braços partindo de uma posição de preparação (2A), passando pela terceira posição (2B) e pela primeira posição dos braços ( $2 C$ e $2 D$ ]. Os pés, respectivamente antes $[2 A$ e $2 B$ ] e depois do giro [2E], estão em quinta posição. A quinta posição dos pés é definida por um calcanhar alinhar-se aos artelhos do outro pé. Após o impulso, durante o giro, a perna elevada mantém uma posição denominada retiré passé $2 C$ e 2D). Para análise do giro do tronco, a posição dos braços em $2 \varepsilon$ foi alterada para segunda posição, que é obtida pela posição dos dois braços estendidos (traçado pontilhado em 2B). mento (condição "com visão" - com olhos abertos normalmente - e condição "sem visão" - com olhos vendados). Na condição com olhos abertos, cada bailarina deveria iniciar a tentativa com seus olhos fechados, abri-los após o sinal do experimentador e dar início ao giro assim que julgasse apropriado. A ordem das condições foi contrabalanceada para evitar os possíveis efeitos de ordem, sendo que metade das participantes executou primeiramente a condição “com visão" e depois a condição "sem visão", enquanto que a outra metade das participantes fez o oposto. A coleta de dados foi realizada individualmente com cada participante, em ambiente apropriado, minimizando interferências visuais e auditivas. Para evitar que o piso ficasse escorregadio, breu foi utilizado na sola das sapatilhas e também no solo, quando necessário. A duração total da coleta de dados foi de aproximadamente 30 minutos.

\section{Análise dos dados}

Inicialmente, cada uma das tentativas filmadas foi digitalizada; a seguir, os marcadores fixados em seus ombros (caracterizando o plano frontal) e na cabeça e nariz (caracterizando o plano sagital) foram manualmente identificadas em cada quadro de cada imagem, para a reconstrução bidimensional dos movimentos de cabeça e tronco. Nove variáveis 
dependentes, cinco de natureza temporal (em s) e quatro de natureza espacial $(\mathrm{em} \mathrm{cm})$, foram escolhidas para caracterizar, respectivamente, o comportamento visual e motor das participantes durante a tarefa, como descritas a seguir:

Olho quieto (OQ): Número de quadros de vídeo entre o momento de abertura completa dos olhos (inclusive o primeiro quadro), no início da tentativa, e o momento anterior ao início do giro do olhar (inclusive o último quadro), multiplicado pelo intervalo de tempo entre os quadros;

Oscilações ântero-posterior (OAP) e médio-lateral (OML) do tronco e cabeça: Diferença entre os valores mínimo e máximo dos marcadores e do ponto médio entre os ombros e o centro da cabeça nas dimensões vertical e horizontal das imagens, respectivamente; Duração do giro do olhar (Dolhar), da cabeça (Dcabeça) e do tronco (Dtronco):_Número de quadros de vídeo entre o primeiro movimento aparente do olhar, do nariz e do braço à frente, respectivamente, multiplicado pelo intervalo de tempo entre os quadros ; Diferença entre as durações dos giros do tronco e da cabeça (Dif_TC): Diferença entre as variáveis Dtronco e Dcabeça.

As variáveis dependentes relativas às oscilações foram obtidas através da reconstrução bidimensional dos movimentos do tronco e cabeça, a partir das imagens da vista superior, enquanto as variáveis dependentes relativas às durações foram obtidas através da inspeção quadro-a-quadro e resultante análise temporal, a partir das imagens da vista frontal. A Figura 3 mostra uma tentativa típica da condição "com visão"; no topo da figura aparecem as informações sobre a identificação da participante, condição e tentativas, assim como os valores calculados para todas as variáveis dependentes; na parte de baixo, são mostradas à esquerda, uma figura do ângulo de rotação do tronco e cabeça em função do tempo, com as durações OQ e Dolhar (indicada por "GO") definidas e, à direita, uma figura das oscilações ântero-posterior e médiolateral do tronco e cabeça. Evidentemente, as variáveis OQ e Dolhar foram obtidas apenas na condição com visão disponível.

Os dados de todas as variáveis, exceto OQ e Dolhar, foram submetidos à análise de variância tendo como fatores Condição (Com visão, Sem visão) e Tentativas (1 a 5), com medidas repetidas nos dois fatores. Os dados de todas variáveis dependentes foram também submetidos ao teste de correlação de Pearson. O nível de significância adotado foi de $\mathrm{p} \leq 0,05$ para todas as análises.

\section{RESULTADOS}

Longos períodos de fixação, mensurados através da variável OQ (olho quieto), estariam relacionados à boa qualidade da execução (16). Como teste desta hipótese, o Quadro 1 mostra os coeficientes de correlação de Pearson obtidos entre todas as variáveis dependentes do estudo. A estabilidade postural durante a execução, representada pelas variáveis de oscilação do tronco e cabeça (OAPc, OMLc, OAPt e OMLt), apresentou pequena correlação negativa com a variável $O Q$, com coeficientes abaixo de 0,3 . Semelhantemente, as outras variáveis dependentes

Quadro 1. Coeficientes de correlação de Pearson entre todas as variáveis dependentes.

\begin{tabular}{|c|c|c|c|c|c|c|c|c|}
\hline & Dolhar & Dcabeça & Dtronco & Dif_TC & OMLt & OAPt & OMLC & OAPC \\
\hline 00 & 0,04 & 0,21 & 0,29 & 0,02 & 0,18 & 0,21 & 0,19 & 0,06 \\
\hline Dolhar & - & 0,18 & 0,09 & 0,09 & 0,12 & 0,21 & 0,21 & 0,38 \\
\hline Dcabeça & & - & 0,15 & 0,74 & 0,41 & 0,04 & 0,34 & 0,03 \\
\hline Dtronco & & & - & 0,55 & 0,13 & 0,17 & 0,07 & 0,24 \\
\hline Dif TC & & & & - & 0,26 & 0,15 & 0,24 & 0,18 \\
\hline OMLT & & & & & - & 0,11 & 0,93 & 0,01 \\
\hline OAPT & & & & & & - & 0,09 & 0,84 \\
\hline OMLC & & & & & & & - & 0,15 \\
\hline OAPC & & & & & & & & - \\
\hline
\end{tabular}


Participante: 1 Condiçấo: COM VISĀO Tentativa: 1

\begin{tabular}{|c|c|}
\hline DURAÇõES (s): & OSCILAÇÕES (cm): \\
\hline Giro do Olhar: 0.6 & OMLt: 9.8279 \\
\hline Giro da Cabeça: 0.73333 & OAPt: 6.0944 \\
\hline Giro do Tronco: 1.6667 & OMLc: 12.4116 \\
\hline Dif. Tronco-Cabeça: 0.93333 & OAPC: 7.0226 \\
\hline
\end{tabular}
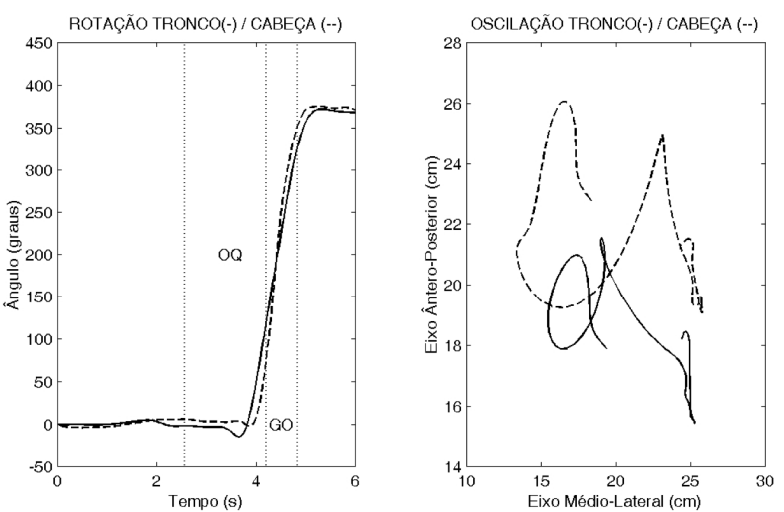

Figura 3. Exemplo de dados de uma tentativa típica (ver texto para detalhes].

que caracterizaram aspectos temporais da execução do giro (duração dos giros do olhar, cabeça e tronco e diferença de duração entre giros do tronco e cabeça), também mostraram-se com coeficientes de correlação muito baixos com a variável OQ. Estesresultados, de modo geral, indicam ausência de associação entre a duração das fixações no início do giro (OQ) e qualquer das medidas temporais e espaciais referentes à qualidade da execução. Cabe salientar, no entanto, que os valores de OQ foram relativamente altos, enquanto as medidas de oscilação corporal (OAPc, OMLc, OAPt e OMLt) foram razoavelmente reduzidas (Quadro 2), atestando o nível habilidoso da execução de bailarinas com, em média, mais de uma década de prática no ballet. Um segundo aspecto em questão neste estudo foi a validade das dicas oferecidas pelos profissionais de ballet, especificamente com relação ao comportamento de "marcar a cabeça". Sobre este aspecto, foi constatado que houve diferença significativa entre as durações dos giros do olhar, cabeça e tronco, como ensinado por eles, no sentido de um sequenciamento claro das partes do corpo envolvidas no giro. A ordem de início dos giros foi consistentemente a do tronco, cabeça e olhar; o término do giro obedeceu ordem inversa. Foi observado que o giro do olhar tem duração menor que os giros da cabeça e do tronco (Quadro 2). Na condição com informação visual disponível, os giros da cabeça tiveram duração menor que os do tronco (diferença tronco-cabeça maior), o que ocorre nitidamente em menor escala na condição sem informação visual disponível (diferença tronco-cabeça menor).

Quadro 2. Média (erro padrão) das variáveis utilizadas no estudo nas condições com e sem informação visual disponível.

\begin{tabular}{lcc}
\hline Variáveis & Com Visão & Sem Visão \\
\hline Duração do giro do olhar & $0.45(0,03)$ & - \\
\hline Duração do giro da cabeça * & $0.57(0,04)$ & $0.91(0,06)$ \\
\hline Duração do giro do tronco & $1.49(0,05)$ & $1.50(0,07)$ \\
\hline Olho Quieto & $1.87(0,11)$ & - \\
\hline $\begin{array}{l}\text { Diferença entre giros } \\
\text { do tronco e cabeça* }\end{array}$ & $0.92(0,06)$ & $0.58(0,07)$ \\
\hline Oscilação ântero-posterior da cabeça* & $9.64(0,74)$ & $13.17(1,20)$ \\
\hline Oscilação ântero-posterior do tronco* & $7.13(0,64)$ & $9.60(0,76)$ \\
\hline Oscilação médio-lateral da cabeça & $10.11(0,80)$ & $12.12(0,84)$ \\
\hline Oscilação médio-lateral do tronco & $7.55(0,77)$ & $8.30(0,58)$ \\
\hline
\end{tabular}

* Diferença significativa entre as condições $(p<0,05)$

Adicionalmente, a influência da disponibilidade de informação visual sobre o movimento do giro foi investigada. A análise de variância monstrou que somente as oscilações ântero-posteriores foram afetadas pela condição de visão. A variável OAPt mostrou-se significativamente reduzida quando havia informação visual disponível, $\mathrm{F}(1,28)=8,39, \mathrm{p}=$ 0,02 . O Quadro 2 mostra as médias (erro padrão) desta e das demais variáveis. Semelhantemente, a OAPc foi significativamente afetada pela disponibilidade de informação visual, $\mathrm{F}(1,28)=9,43$, $\mathrm{p}=$ 0,02 . Por outro lado, as oscilações médio-laterais mostraram comportamento distinto. As variáveis 
OMLc e OMLt não foram significativamente afetadas pelo fator visão, respectivamente, $\mathrm{F}(1,28)=3,64$, $\mathrm{p}$ $=0,10$ e $\mathrm{F}(1,28)=0.88, \mathrm{p}=0,38$.

\section{DISCUSSÃo}

Esperava-se que a variável OQ estivesse associada ao sucesso da performance, com valores mais elevados para melhores resultados. Esta hipótese foi testada através da análise das correlações entre OQ e as demais variáveis dependentes do estudo, em especial as referentes à oscilação corporal. Muito embora a duração média de OQ tenha sido relativamente alta (acima de 1,5 s), assim como as oscilações de tronco e cabeça tenham sido relativamente baixas (de 7 a $13 \mathrm{~cm}$ ), as associações entre estas variáveis foi basicamente inexistente. O mecanismo do OQ foi anteriormente identificado em uma variedade de situações, como a da batida do golfe(15), do lance livre do basquetebol(16), a recepção do voleibol(18), arremesso de dardos(20), tênis de mesa(12) e speed skating ${ }^{(17)}$. No presente estudo, esperava-se uma relação do período de aquisição de informação visual com a qualidade da performance motora; ou seja, que fixações mais longas estivessem associadas à menor instabilidade postural. Os dados não confirmaram as expectativas, pois os resultados não apontaram correlações negativas elevadas entre as variáveis OQ e oscilações corporais.

A hipótese de associação entre a duração do OQ e a qualidade da performance (16) poderia ser confirmada de dois modos: através da comparação entre os grupos experts e quase experts, e através da comparação entre os acertos e os erros. Diferentemente do presente estudo, no caso do lance livre do basquetebol, tanto os experts apresentaram OQ mais longos do que os quase experts, quanto os experts apresentaram $\mathrm{OQ}$ mais longos em seus acertos do que em seus erros $(16)$.

Outros estudos não confirmaram a hipótese do OQ simultaneamente nos dois aspectos. Na situação de recepção do voleibol(18), o OQ foi observado apenas no grupo dos experts, mas diferenças entre acertos e erros não foram reportadas. Adicionalmente, não apenas a duração do OQ pode influenciar a qualidade da performance, mas também o seu início no tempo. Em contexto de tênis de mesa(12), o grupo menos habilidoso apresentou o início do OQ mais tarde durante os erros do que durante os acertos, enquanto os mais habilidosos não diferiram neste aspecto. Por outro lado, a experiência dos mesatenistas não afetou a duração do OQ.

No presente estudo, as bailarinas que tinham mais de dez anos de experiência, apresentaram longos períodos de OQ e pequenas oscilações corporais, mas todos com baixa variabilidade, o que talvez tenha ocultado a natureza compensatória entre duração da aquisição de informação visual relevante e qualidade do controle postural; a utilização de um grupo de bailarinas não tão experientes poderia ter revelado tais expectativas.

Um aspecto que merece debate é a suficiência da informação obtida durante o período de fixação do olhar antes do início do giro. É sugerido que a variável OQ reflete um período ótimo de aquisição de informação relevante para o controle de ação(16, 19, 20, 21), o que indica que a regra de quanto mais longa a fixação, melhor a performance motora deve ser relativizada. As bailarinas deste estudo parecem ter fixado o olhar à frente por tempo suficientemente longo para gerar equilíbrio dinâmico necessário para o sucesso da pirouette. Os valores de OQ foram consistentemente altos para todas as tentativas, mostrando a existência de uma fase inicial relativamente longa de aquisição de informação relevante para a ação, antes de seu início. É durante este período que os parâmetros da ação estão sendo definidos (16), o que requer, no caso da pirouette, informações sobre o relacionamento do corpo com o ambiente para garantir estabilidade na performance motora. A literatura revisada mostra claramente que a magnitude do OQ é variável e bastante dependente das demandas do ambiente e da tarefa a ser realizada. O OQ de jogadores de basquetebol foi de aproximadamente $970 \mathrm{~ms}$ nos acertos e $810 \mathrm{~ms}$ nos erros; de mesatenistas experientes e iniciantes foi igualmente de aproximadamente $420 \mathrm{~ms}$ (na condição controle); e de jogadores experientes de voleibol aproximadamente $430 \mathrm{~ms}$.

É possível que as medidas escolhidas para a análise da instabilidade postural tenham sido eficazes para fazer a reconstrução da trajetória do movimento, porém talvez não tenham fornecido informações suficientes para representar apropriadamente a instabilidade. A habilidade pirouette é extremamente 
complexa, e é composta por inúmeros detalhes de execução. É plausível que outros aspectos do giro tenham provocado diferenças na oscilação, no entanto não puderam ser captados pelas variáveis adotadas. De modo similar, o método utilizado foi limitado à análise temporal do comportamento do olhar; informações sobre a localização das fixações poderiam ter melhor caracterizado a variável $\mathrm{OQ}$ dispensando o artifício de solicitar às bailarinas que fechassem os olhos para dar início às tentativas da condição com olhos abertos.

Uma outra possibilidade de explicação para a ausência de correlações do OQ com a estabilidade postural seria relacionada à complexidade da ação. Talvez giros ainda mais complexos tornassem as bailarinas ainda mais dependentes das longas fixações do olhar à frente, desvendando a preponderância deste tipo de variável (e.g., OQ) sobre a qualidade da performance. Os profissionais do ballet garantem que "marcar a cabeça", mais do que qualquer outro aspecto da execução, é a estratégia imprescindível para o sucesso nesses tipos de movimentos. Novos estudos com tarefas de giro ainda mais complexas podem ajudar a esclarecer os efeitos de longos períodos de aquisição de informação visual e outras informações sensoriais durante a performance habilidosa. O "marcar a cabeça" foi observado nos resultados; as participantes exibiram clara seqüência de durações: no começo da ação, o início do giro do tronco se dá primeiramente, seguido do início do giro da cabeça, e por último o início do giro do olhar; no final da ação, a seqüência se dá na seguinte ordem: término do giro do olhar primeiramente, seguida do término do giro da cabeça e encerrada com o término do giro do tronco. Esta seqüência foi mantida durante os giros, mesmo com o fator visão afetando as diferenças tronco-cabeça na condição sem visão disponível. A presença de uma seqüência muito bem definida de início da orientação das partes do corpo também foi observada em um estudo cujos resultados indicaram que, numa tarefa de apontar, os olhos iniciaram seu movimento primeiramente, seguido da cabeça, tronco e pés(8). Apesar da ordem distinta, estes resultados semelhantemente aos das bailarinas do presente estudo, sugerem que a ordem de atuação dos membros parece ser um aspecto importantíssimo do planejamento e execução das ações.
Interessantemente, quando a visão foi removida, na condição sem informação visual, os movimentos da cabeça e do tronco mostram-se acoplados. Os dados cinemáticos das tentativas mostram com clareza peculiar como a cabeça está conectada com o olhar em termos de controle, atrasando o máximo possível o início de seu giro em relação ao tronco. Nestas circunstâncias, fica nítido que o olhar funciona como uma "âncora" para o sistema de controle postural(12, $15,16,17)$, procurando manter-se o máximo de tempo relativo estabilizado em uma localização à frente, e fazendo seu giro o mais rápido possível.

A literatura revisada mostra completa concordância com o efeito da retirada da informação visual sobre a estabilidade postural(2, 6, 7), e um destes estudos(10) mostra uma particularidade relacionada à experiência de executantes altamente treinados, como é o caso das bailarinas deste estudo. Judocas foram menos sensíveis à retirada da informação visual que bailarinas; talvez esta seja uma especificidade da modalidade, uma vez que judocas parecem relativamente menos dependentes da visão, porque estão em contato físico, agarrados aos seus oponentes quase todo o tempo de luta, ao passo que bailarinas não são requeridas em suas apresentações a atuarem sem informação visual disponível; por outro lado, as bailarinas são ensinadas a utilizar marcações espaciais constantemente, como os dados sobre "marcar a cabeça" indicam neste estudo, o que reforça a dependência da visão.

A condição sem informação visual disponível tornou as oscilações ântero-posteriores significativamente mais elevadas que as oscilações médio-laterais. Uma possível explicação para a ocorrência desse fato pode ser a posição dos pés das bailarinas quando executam a pirouette en dehors de quinta posição. As cinco posições dos pés no ballet clássico são en dehors, o que significa "para fora"(13). Como ilustrado na Figura 2, a quinta posição dos pés deve ser mantida na direção médio-lateral durante todo o giro. Distintamente, a posição "natural" dos nossos pés, tende a reduzir a instabilidade no sentido ânteroposterior das bailarinas. Desprovida de informação visual, a percepção corporal das bailarinas durante o giro foi provavelmente alterada, prejudicando a oscilação ântero-posterior, apesar dessa medida já ser deteriorada pela exigência da modalidade, visto que 
todos os movimentos são executados en dehors. Embora os dados não tenham indicado que maiores durações de OQ tragam benefícios significativos para a instabilidade corporal, a alta habilidade das bailarinas participantes revelou-se através das elevadas durações do OQ e reduzidas taxas de oscilação nas duas direções.

A execução da pirouette pode ser entendida como contendo a atividade de busca visual por alvos específi$\cos ^{(14)}$. É sugerido que o treinamento da antecipação do movimento de retornar ao alvo pode compensar retardos naturais do processamento da informação visual. As bailarinas com aproximadamente uma década de prática já atingiram um alto nível de automatização do "marcar a cabeça", conforme os presentes resultados indicam, o que, presume-se, tenha beneficiado o controle motor e também a percepção do giro, possibilitando performances mais consistentes. Bailarinas com este nível de experiência são capazes de executar giros ainda mais complexos, como variações das pirouettes: dupla pirouette, tripla pirouette, e até os denominados tours (giros em geral, podendo conter até 21 voltas em um só movimento).

Conclui-se que, embora a forte associação entre $\mathrm{OQ}$ e controle postural não tenha sido demonstrada, o sucesso e a elevada qualidade da performance da pirouette do ballet são altamente dependentes das estratégias de aquisição de informação visual. A seqüência de durações dos giros do tronco, cabeça e olhar foi observada, confirmando a validade das dicas sobre como "marcar a cabeça" fornecida por profissionais do ballet. A condição sem informação visual mostrou o acoplamento dos movimentos da cabeça e do tronco, sinalizando a importância da visão no controle de ações complexas como os giros.

\section{AGRADECIMENTOS}

Este trabalho teve apoio financeiro da Fundação de Amparo à Pesquisa do Estado de São Paulo (processo $04 / 10193-1$ ).

Os dados do presente estudo foram apresentados sumariamente e de modo parcial em mesa redonda do XI Congresso de Ciências do Desporto e Educação Física dos Países de Língua Portuguesa, São Paulo - SP, em Setembro de 2006.

\section{CORRESPONDÊNCIA}

\section{Sérgio Tosi Rodrigues}

Laboratório de Informação, Visão e Ação (LIVIA)

Departamento de Educação Física

Faculdade de Ciências

Universidade Estadual Paulista - Campus Bauru

Av. Eng. Luis Edmundo Corrijo Coube, 14-01 Vargem Limpa

Bauru, SP, Brasil, CEP: 17033-360

E-mail: srodrigu@fc.unesp.br 


\section{REFERÊNCIAS}

1. Achcar D (1986). Ballet: Arte, técnica, interpretação. Rio de Janeiro: Cia. Brasileira de Artes Gráficas.

2. Buchanan J, Horak FB (1999). Emergence of postural patterns as a function of vision and translation frequency. $J$ Neurophysiol 81: 2325-2339.

3. Daniel BM, Lee, DN (1990). Development of looking with head and eyes. J Exp Child Psychol 50: 200-216.

4. Gibson JJ (1966). The senses considered as perceptual systems. Boston: Houghton Mifflin.

5. Gibson JJ (1979). The ecological approach to visual perception. Hillsdale, NJ: Lawrence Erlbaum Associates.

6. Golomer E, Cre'mieux J, Dupui P, Isableu B, Ohlmann T. (1999). Visual contribuition to self-induced body sway frequencies and visual perception of male professional dancers. Neurosci Lett 267: 189-192.

7. Golomer E, Dupui P, Séréne P, Monod H (1999). The contribuition of vision in dynamic spontaneous sways of male classical dancers according to student or professional level. J Physiol (Paris) 93: 233-237.

8. Hollands MA, Ziavra NV, Bronstein AM (2004). A new paradigm to investigate the roles of head and eye movements in the coordination of whole-body movements. Exp Brain Res 154: 261-266.

9. Martell SG, Vickers JN (2004). Gaze characteristics of elite and near-elite athletes in ice hockey defensive tactics. Hum Mov Sci 22: 689-712.

10. Perrin P, Deviterne D, Huget F, Perrot C (2002). Judo, better than dance, develops sensorimotor adaptabilities involved in balance control. Gait \& Posture 15: 187-194.

11. Ripoll H, Bard C, Paillard J (1986). Stabilization of head and eyes on target as a factor in successful basketball shooting. Human Mov Sci 5: 47-58.

12. Rodrigues ST, Vickers JN, Williams AM (2002). Head, eye and arm coordination in table tennis. J Sports Sci 20: 187200.

13. Rosay M (1980). Dicionário de ballet. Rio de Janeiro: Nórdica.

14. Stork S, Neggers SFW, Müsseler J (2002). Intentionallyevoked modulations of smooth pursuit eye movements. Human Mov Sci 21: 335-348.

15. Vickers JN (1992). Gaze control in putting. Perception 21: 117-132.

16. Vickers JN (1996). Visual control when aiming at a far target. J Exp Psychol Human Percept Perform 22: 342-354.

17. Vickers JN (2006). Gaze of Olympic speedskaters skating at full speed on a regulation oval: Perception-action coupling in a dynamic performance environment. Cogn Process 7: 102-105.

18. Vickers JN, Adolphe RM (1997). Gaze behaviour during a ball tracking and aiming skill. Int J Sports Vis 4: 18-27.

19. Vickers JN, Rodrigues ST, Brown LN (2002). Gaze pursuit and arm control of adolescent males diagnosed with attention deficit disorder (ADHD) and normal controls: Evidence of a dissociation in processing visual information of short and long duration. J Sports Sci 20: 201-216.

20. Vickers JN, Rodrigues ST, Edworthy G (1999). Quiet eye and accuracy in the dart throw [Resumo]. International Society of Biomechanics 17: 819.

21. Williams AM, Vickers JN, Rodrigues ST (2002). The effects of anxiety on visual search, movement kinematics, and performance in table tennis: A test of Eysenck and Calvo's processing efficiency theory. J Sport Exerc Psychol 24: 438-455. 